\title{
The Brazilian Journal of Geology is born. Long life to it!
}

For the members of the geological community of Brazil, the Revista Brasileira de Geociências (RBG) has been the most obvious locus to submit their scientific contributions for more than 40 years. With Volume 43, RBG changes not only its title and graphical project, but mainly its focus as it seeks to establish itself among the best international publications in the Earth Sciences. With an open-access electronic version, the Brazilian Journal of Geology (BJG) provides an international medium and a regional reference for publication of matters concerned with all aspects of Geological Sciences in Brazil, neighboring countries and the South Atlantic in general, including Antarctica.

I consider that the initial goals proposed by the Sociedade Brasileira de Geologia (SBG) for restructuring RBG have been reached in a very satisfactory way. RBG's new scope and objectives have been in place since mid-2012, and with this issue 43(1) new instructions are given to the authors. The recently appointed Editorial Council is already evaluating submitted manuscripts according to new procedures in action for referees. The operation of the editorial of the Open Journal System (OJS) is managed in a routine way by professionals of Zeppelini Editorial House. Punctuality and indexation in SCOPUS (Elsevier) have already been achieved, respectively in 2011 and 2012, and the main targets now are to maintain editorial operation and regularity of publication, and look for indexation in the international databases - Scientific Electronic Library Online (SciELO) and Institute of Scientific Information (ISI).

We must always keep in mind our ultimate target, which is to acquire international recognition. Obviously, it has to do with the quality of the published papers, and I have complete confidence in the Brazilian geological community as a source of excellent material. In the international literature, we can find numerous articles written by Brazilian geologists on matters of great interest for the Earth Sciences. If the present flux of submissions to the BJG is maintained, bringing in good material with regional appeal, and with the control by competent editors and reviewers, I have no doubts that this ultimate goal will be fulfilled.

However, there is a condition for if we wish that BJG become an internationally visible scientific publication - scientific quality and regularity must be maintained and a significant number of its articles must be written in English. Very few Earth scientists outside the Portuguese-speaking countries can read Portuguese, so it is fundamental that BJG authors be convinced of the benefits of global visibility. Our Editorial Council made it very clear when included the following statement within the scope of the journal: "English language is preferred, although submissions in Portuguese and Spanish are accepted”. Several Brazilian scientific societies analogous to SBG have published their journals in English for many years, and these are indexed within ISI. A few examples are the Brazilian Journal of Physics, the Brazilian Journal of Analytical Chemistry, the Brazilian Journal of Biology, among others. The Brazilian Journal of Geophysics, edited by the Brazilian Geophysical Society, began publishing all its articles in English last year.

To conclude, I want to acknowledge the very positive response from the Brazilian geological community regarding the new trends of the Revista Brasileira de Geociencias/Brazilian Journal of Geology and I emphasize the necessity of maintaining the influx of qualified submissions. This response is very important to guide us toward an appropriate international insertion. I also want to thank to the colleagues of the Editorial Council, which are listed in the internal cover of the RBG/BJG. The Brazilian Councillors are already providing a great deal of competent help with direct editorial work; the foreign members have accepted with pleasure to become our partners, and they are ready to start direct editorial operation during 2013. Finally, it is important to mention the continued support provided by the Board of Directors of the SBG during this initial and sometimes difficult phase of restructuring RBG, and especially for the administrative and financial efforts made in order to assure the needed resources to maintain the publication.

Umberto G. Cordani Editor-Chefe 